\title{
Sphincter preservation in distal CT2N0 rectal cancer after preoperative chemoradiotherapy
}

\author{
Nir Wasserberg ${ }^{1 *}$, Yulia Kundel ${ }^{2,3}$, Ofer Purim²,3, Andrei Keidar ${ }^{1}$, Hanoch Kashtan ${ }^{1}$, Eran Sadot ${ }^{1}$, Eyal Fenig ${ }^{2,3}$ \\ and Baruch Brenner ${ }^{2,3}$
}

\begin{abstract}
Background: Preoperative chemoradiotherapy is usually not indicated for cT2NO rectal cancer. Abdominoperineal resection is the standard treatment for distal rectal tumors. The aim of the study was to evaluate the actual sphincter-preservation rate in patients with distal CT2NO rectal cancer given neoadjuvant chemoradiotherapy.

Methods: Data were retrospectively collected for all patients who were diagnosed with distal cT2N0 rectal cancer at a tertiary medical center in 2000-2008 and received chemoradiotherapy followed by surgery (5-7 weeks later).

Results: Thirty-three patients (22 male) of median age 65 years (range, 32-88) were identified. Tumor distance from the anal verge ranged from 0 to $5 \mathrm{~cm}$. R0 resection with sphincter preservation was accomplished in 22 patients (66\%), with a 22\% pathological complete response rate. Median follow-up time was 62 months (range 7-120). There were no local failures. Crude disease-free and overall survival were $82 \%$ and $86 \%$, respectively. Factors associated with sphincter preservation were tumor location $(\mathrm{OR}=0.58, \mathrm{p}=0.02,95 \% \mathrm{Cl}=0.37-0.91)$ and pathological downstaging $(\mathrm{OR}=7.8, \mathrm{p}=0.02,95 \% \mathrm{Cl}=1.35-45.85)$. Chemoradiotherapy was well tolerated.
\end{abstract}

Conclusion: High rates of sphincter preservation can be achieved after preoperative chemoradiotherapy for distal cT2NO rectal cancer, with tolerable toxicity, without compromising oncological outcome.

Keywords: T2 rectal cancer, Preoperative chemoradiotherapy, Sphincter preservation, Low anterior resection, Abdominoperineal resection

\section{Background}

The main aims of rectal cancer treatment are locoregional control and improvement of overall and diseasefree survival. Currently, the standard treatment for rectal cancer consists of radical surgery with total or partial tumor-specific mesorectal excision. Short-course radiotherapy or long- course chemoradiotherapy (CRT) may be administered preoperatively, depending on the location of the tumor in the rectum and the disease stage [1]. For patients with very low-lying rectal tumors, abdominoperineal resection (APR) is the traditional method of choice [2]. However, the use of sphincter-sparing procedures has been increasing [3] owing to advances in surgical technique and instruments, the introduction of specialized high-volume centers, and an improved understanding of the sphincter mechanism and the tumor biology [1].

\footnotetext{
* Correspondence: nirw@clalit.org.il

'Department of Surgery B, Petach Tikva 49100, Israel

Full list of author information is available at the end of the article
}

Consequently, sphincter-sparing surgery is now considered a desirable endpoint also in this patient group when it is technically, functionally, and oncologically feasible [4].

In terms of disease stage, preoperative CRT or radiotherapy is indicated for locally advanced cT3 and/or $\mathrm{N}+$ rectal tumors [5] to improve local control [6]. However, given its high toxicity, CRT is difficult to justify for patients with cT2N0 rectal cancer, in whom it has not been associated with considerable oncological improvement $[7,8]$. Nevertheless, CRT might be applicable in some cases in order to avoid APR when low anterior resection (LAR) is otherwise unfeasible.

There is some evidence that preoperative CRT, by downstaging and downsizing the tumor, may also benefit sphincter preservation $[9,10]$. Yet, because it is rarely used to treat early-stage disease, only sparse data are available on the actual rate of sphincter preservation in patients with distal cT2N0 rectal cancer who received CRT before surgery. In the only published trial that 
specifically addressed this issue, Rengan and colleagues [11] demonstrated that in patients with distal cT2N0 rectal cancer who require $\mathrm{APR}$, preoperative pelvic irradiation improved sphincter preservation without any apparent cost to local control or survival. The aim of the present study was to evaluate the rate of sphincter preservation when preoperative CRT is used in an attempt to avoid APR in patients with distal cT2N0 rectal tumors.

\section{Methods}

\section{Patients}

The electronic database of a tertiary medical center was searched for all patients with rectal cancer treated by long-course CRT followed by curative surgical resection in 2000 to 2008. Among the 324 patients identified, we selected those with distal cT2N0 disease who were being clinically considered by their surgeons for an APR and were referred for preoperative CRT to increase the probability of a sphincter-preserving procedure. The diagnosis was confirmed on histological study in all cases, and staging was confirmed by thoracic and abdomino-pelvic computerized tomography, tocheck for distal metastasis, and endoscopic rectal ultrasound, for local evaluation.

\section{Treatment}

Radiation was delivered with 6 or18 MV photons using a three-field belly-board technique. The superior border was placed at the L5-S1 interspace, and the inferior border was 3 to $4 \mathrm{~cm}$ distal to the tumor; in all cases, the inferior border was at or distal to the obturator foramen. In order to encompass the iliac lymph node chain, the lateral borders of the posterior portal were $1.5 \mathrm{~cm}$ outside the true bony pelvis. The lateral fields encompassed the sacrum and coccyx posteriorly and the femoral head anteriorly to include the obturator nodes.

The delineation of the planning target volume (PTV), gross total volume (GTV) and clinical target volume (CTV) was as follows. The whole pelvis (PTV1) including the primary tumor (GTV), internal, presacral, obturator, and perirectal lymph nodes (CTV1), received a total of $45 \mathrm{~Gy}$, with the dose prescribed to the $95 \%$ isodose line using standard fractions of $1.8 \mathrm{~Gy} /$ day. This was followed by a reduced field boost (PTV2) delivered by the same technique (posterior and 2 lateral fields) to a smaller treatment volume that included the tumor (GTV) and a 2- to 3-cm margin for an additional 5.4 Gy.

Surgery was performed 5-7 weeks after completion of CRT. The type of surgery was left to the discretion of the operating surgeon. Postoperative management was based on the pathological staging.

\section{Data collection}

For the present study, the following data were retrieved from the medical files of the eligible patients: demographics, pretreatment staging, findings on physical examination, rigid and flexible endoscopy, and local and systemic imaging, in addition to the toxicity assessment during preoperative treatment [according to the NCI (National Cancer Institute) Common Toxicity Criteria, Version 3 type of surgery, pathology results, and findings on follow-up.

The study was approved by the institutional review board.

\section{Statistical analysis}

Outcome measures were rates of sphincter preservation, overall survival (OS), and disease-free survival (DFS) including local and distant recurrence. Univariate logistic regression was applied to analyze putative predictors of sphincter preservation. Significance was defined as $\mathrm{p}<0.05$. OS was calculated from the date of surgery to death or the last date the patient was known to be alive. DFS was calculated from the date of surgery to the first documented recurrence or the last date the patient was known to be free of recurrence. OS and DFS were estimated using the Kaplan-Meier method and compared between patients who underwent LAR or APR using the log-rank test.

\section{Results}

\section{Patients}

Thirty-three patients were eligible for inclusion in the study: 22 (66\%) male and 11 female of median age 65 years (range $32-88$ ). Distance of the tumor from the anal verge ranged from 0 to $5 \mathrm{~cm}$ on rigid rectoscopy. Twenty-two patients (66\%) underwent LAR with sphincter preservation and 11 underwent APR. All patients had an R0 resection with clear distal and circumferential margins. The tumor was downstaged after CRT in 14 patients (42\%), of whom 7 (22\% of the entire group) had pT1 and 7 (22\% of the entire group) had a pathological complete response (pCR). There were no significant differences in tumor charecteristics between tumors with or without pathological downstaging (Table 1). Advanced pathological stage pT3 was found in 2 patients overall, and positive $\mathrm{N} 1$ was found in one patient. Table 2 describes the preoperative patient and tumor characteristics by type of surgery performed, and Table 3 describes the postoperative results.

\section{Predictors of sphincter preservation}

Factors associated with sphincter preservation (Table 4) were tumor distance from the anal verge $(\mathrm{OR}=0.58$, $\mathrm{p}=0.02,95 \% \mathrm{CI}=0.37-0.91$ for every centimeter distance) and pathological downstaging including $\mathrm{pCR}(\mathrm{OR}=7.8$, $\mathrm{p}=0.02,95 \% \mathrm{CI}=1.35-45.85)$. There was no association with patient age, sex or tumor size, fixation, percentage circumference, or preoperative ultrasound staging Longterm outcome. 
Table 1 Tumor characteristics in 33 patients by pathological downstaging vs. no pathological downstaging

\begin{tabular}{|c|c|c|}
\hline $\begin{array}{l}\text { No pathological } \\
\text { downstaging } \\
(n=19)\end{array}$ & $\begin{array}{l}\text { Pathological } \\
\text { downstaging } \\
(n=14)\end{array}$ & Characteristics \\
\hline $\begin{array}{l}\text { Pre-CRT serum CEA level (mcg/L), } \\
\text { mean } \pm S D\end{array}$ & $5.4 \pm 4.7$ & $15.9 \pm 40.7$ \\
\hline Tumor diameter (cm), median (range) & $4(2-12)$ & $5(1-13)$ \\
\hline Tumor fixation, \% & 2 & 2 \\
\hline \% circumference, median (range) & $50(30-100)$ & $60(30-100)$ \\
\hline Tumor grade, n (\%) & & $2(10)$ \\
\hline 1 & $4(28)$ & $13(68)$ \\
\hline 2 & $7(50)$ & $4(21)$ \\
\hline 3 & $3(21)$ & \\
\hline Mucin, $\mathrm{n}$ & 1 & 2 \\
\hline Lymphovascular or perineural invasion, $\mathrm{n}$ & 2 & \\
\hline
\end{tabular}

CRT - chemoradiotherapy, CEA - carcinoembryonic antigen.

The median duration of follow-up was 62 months (range, 7-112 months): 54 months for the LAR group (range, 7-112 months) and 89 months for the APR group (range, 23-110 months). There were no local failures in either group. Distant recurrence was documented in 3 patients in the APR group (27\%) and 2 in the LAR group (9\%). The estimated 5-year OS was $77 \%$ for the entire cohort (Figure 1), $80 \%$ for the APR group, and $75 \%$ for the

Table 2 Clinical characteristics in 33 patients with distal cT2NO rectal cancer by type of surgery

\begin{tabular}{|c|c|c|}
\hline Characteristics & $\operatorname{APR}(n=11)$ & $\operatorname{LAR}(n=22)$ \\
\hline Age (yr), median (range) & $67(60-77)$ & $64(32-88)$ \\
\hline \multicolumn{3}{|l|}{ Gender, n (\%) } \\
\hline Male & $7(63)$ & $15(68)$ \\
\hline Female & $4(37)$ & $7(32)$ \\
\hline \multicolumn{3}{|l|}{ Clinical staging, $n(\%)$} \\
\hline cT2 & $11(100)$ & $22(100)$ \\
\hline $\mathrm{cNO}$ & $11(100)$ & $22(100)$ \\
\hline Tumor diameter $(\mathrm{cm})$, median (range) & $5(3-8)$ & $5(2-13)$ \\
\hline$\%$ circumference, median (range) & $45(30-100)$ & $60(30-100)$ \\
\hline Tumor fixation, n (\%) & $2(18)$ & 2(9) \\
\hline \multicolumn{3}{|l|}{ Tumor grade, n (\%) } \\
\hline 1 & $1(9)$ & $5(22)$ \\
\hline 2 & $7(63)$ & 13(59) \\
\hline 3 & $3(27)$ & $4(18)$ \\
\hline Mucin, n (\%) & $0(0)$ & $1(4)$ \\
\hline \multicolumn{3}{|l|}{ Distance from anal verge $(\mathrm{cm})$, } \\
\hline Median (range) & $3(0-5)$ & $4(0-5)$ \\
\hline
\end{tabular}

APR-abdominoperineal resection, LAR-low anterior resection.
Table 3 Postoperative results in 33 patients with distal cT2NO rectal cancer by type of surgery

\begin{tabular}{llll}
\hline Characteristics & $\begin{array}{l}\text { APR } \\
(\mathbf{n = 1 1 )}\end{array}$ & $\begin{array}{l}\text { LAR } \\
(\mathbf{n = 2 2})\end{array}$ & $\begin{array}{l}\text { Total } \\
(\mathbf{n}=\mathbf{3 3})\end{array}$ \\
\hline R0 resection * & 11 & 22 & 33 \\
pT3 & 2 & 0 & $2(6 \%)$ \\
Pathological downstaging & 2 & 12 & $14(42 \%)$ \\
PT1 & 1 & 6 & $7(22 \%)$ \\
pCR & 1 & 6 & $7(22 \%)$ \\
Tumor grade & & & \\
1 & 2 & 5 & 7 \\
2 & 5 & 13 & 18 \\
3 & 4 & 4 & 8 \\
Mucin & 3 & 0 & 3 \\
Lymphovascular or perineural invasion & 2 & 1 & 3 \\
Number of retrieved lymph nodes, & $6(3-16)$ & $5(3-11)$ & $8(4-17)$ \\
minn (range)
\end{tabular}
median (range)

\begin{tabular}{llll}
$\mathrm{pN} 1$ & 1 & 0 & 1 \\
\hline
\end{tabular}

*Proximal, distal, and radial margins.

APR-abdominoperineal resection, LAR-low anterior resection.

Values are $\mathrm{n}$ or $\mathrm{n}(\%)$ unless otherwise indicated.

LAR group (Figure 2). DFS for the whole cohort was 76\%; the estimated rate was $70 \%$ for the APR group and $80 \%$ for the LAR group. There was no statistically significant between-group difference in either OS or DFS.

\section{CRT toxicity}

CRT was well tolerated (Table 5). Grade 3 thrombocytopenia was documented in $13 \%$ of patients, but there were no other cases of severe toxicity and no treatmentrelated admissions. The most common side effect was grade 1-2 dermal reaction, in $30 \%$ of patients. A lowgrade gastrointestinal reaction occurred in less than $20 \%$ of patients, and only one patient complained of severe anal pain. There were no treatment-related deaths.

Table 4 Factors associated with sphincter preservation (univariate analysis)

\begin{tabular}{llll}
\hline Factor & OR & $\mathbf{P}$ value & $\mathbf{9 5 \%} \mathbf{C l}$ \\
\hline Distance from anal verge & 0.58 & 0.02 & $0.37-0.91$ \\
Age & 1 & 0.2 & $0.9-1.1$ \\
Sex & 1.2 & 0.9 & $0.26-5.6$ \\
Tumor size & 0.8 & 0.4 & $0.6-1.2$ \\
\% circumference & 0.9 & 0.6 & $0.5-1.7$ \\
UT downstaging & 3.9 & 1.45 & $0.6-25$ \\
pT downstaging & 7.8 & 0.02 & $1.35-45.85$ \\
\hline
\end{tabular}

pT-pathological tumor, uT, ultrasound observation of T stage. 


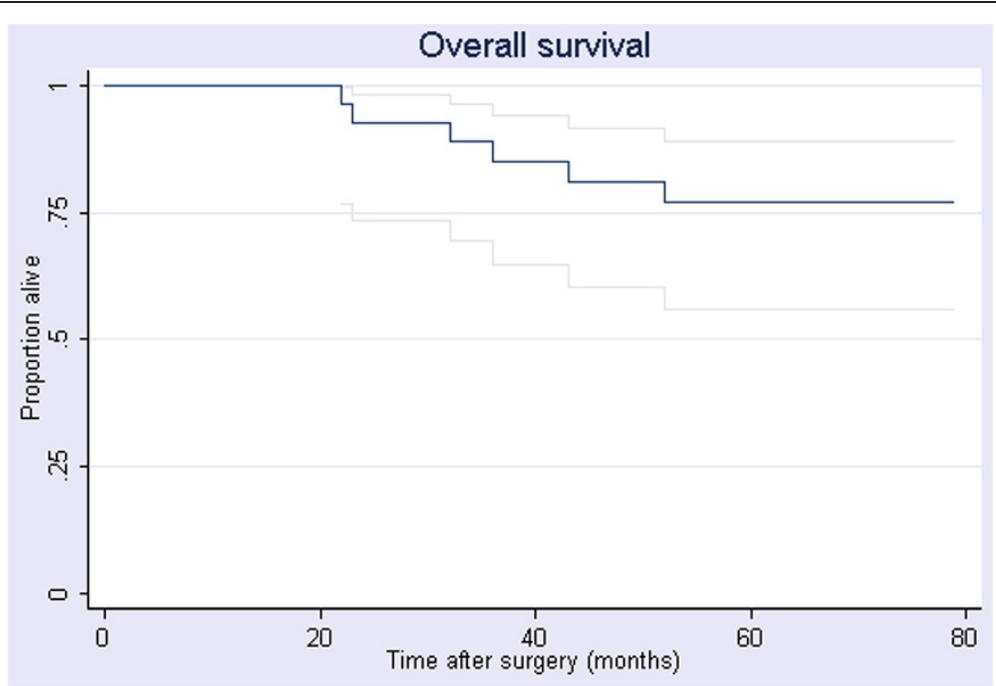

Figure 1 Kaplan-Meier estimated 5-year overall survival in 33 patients with cT2NO rectal cancer treated with CRT followed by surgery.

\section{Discussion}

Efforts to preserve the sphincter in rectal cancer surgery are based on oncological, anatomical, and technical considerations in addition to the patient's co-morbid status and his or her desire. The present study indicates that preoperative CRT may benefit patients with distal cT2N0 tumors in terms of an increased rate of sphincter preservation without compromising the oncological outcome.

Our finding supports earlier claims of an improvement in sphincter preservation after preoperative CRT $[9,12]$. However, the issue remains controversial. The German Rectal Cancer Study Group [6] found that preoperative CRT was associated with a significantly higher incidence of sphincter preservation than postoperative CRT in patients clinically considered for APR before treatment, but there was no difference in the overall rate of sphincter preservation between the groups. The body of evidence from randomized clinical trials [13-15] did not support the benefit of preoperative CRT for sphincter preservation, although in the Lyon R90-01 trial [13], a trend was noted toward more conservative surgery, especially in low rectal tumors ( $41 \%$ vs. $23 \%$ ), after a longer interval between CRT and surgery. Specific data for patients with low cT2 rectal cancer are limited. Some reports on mixed populations including patients with cT2 tumors $[14,16]$ noted high rates of sphincter preservation after preoperative CRT. In the study of Rengan et al. [11], of 27 patients with cT2N0 distal rectal tumors who received preoperative CRT, 78\%

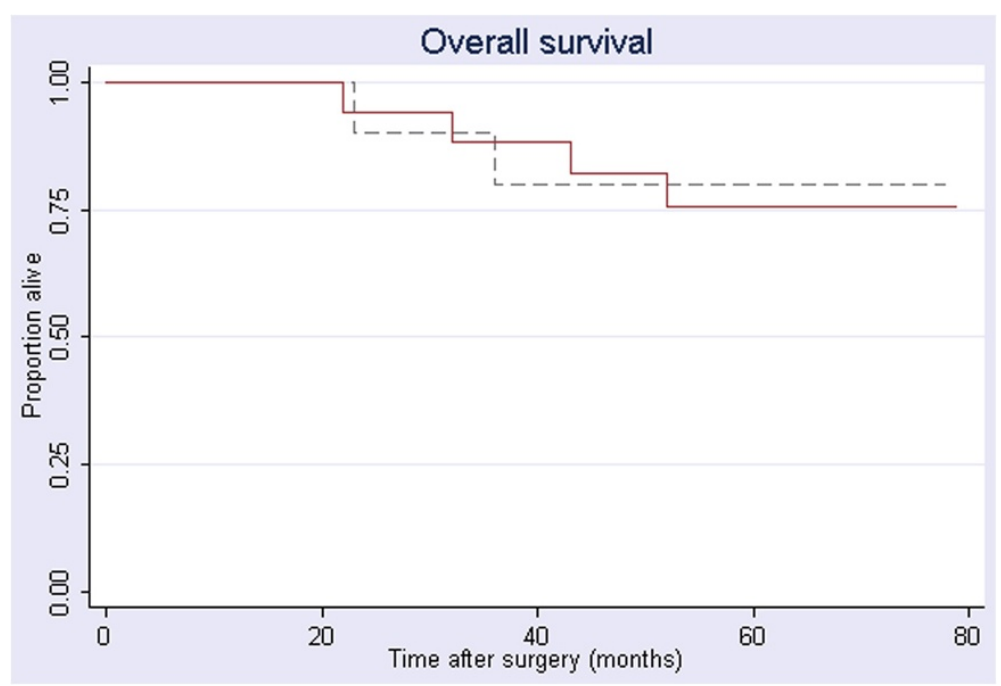

Figure 2 Kaplan-Meier estimated 5-year overall survival in 33 patients with cT2NO rectal cancer treated with CRT followed by surgery, by type of surgery. 
Table 5 Toxic effect of CRT in 33 patients with distal cT2NO rectal cancer

\begin{tabular}{llllll}
\hline Toxicity & \multicolumn{2}{c}{ Grade 1-2 } & & \multicolumn{2}{c}{ Grade 3-4 } \\
\cline { 2 - 3 } \cline { 5 - 6 } & Number & \% & & Number & $\%$ \\
\hline Hematological & 2 & 6 & 0 & 0 \\
Neutropenia & 0 & 0 & 0 & 0 \\
Neutropenic fever & 3 & 9 & 0 & 0 \\
Anemia & 0 & 0 & 3 & 13.0 \\
Thrombocytopenia & 1 & 3 & 0 & 0 \\
Bleeding & & & & 0 \\
Nonhematological & 1 & 3 & 0 & 0 \\
Nausea & 0 & 0 & 0 & 0 \\
Vomiting & 0 & 0 & 0 & 0 \\
Fatigue & 4 & 10 & 0 & 0 \\
Diarrhea & 1 & 3 & 0 & 0 \\
Stomatitis & 10 & 30 & 0 & 0 \\
Dermal & 0 & 0 & 0 & 0 \\
Anorexia & 5 & 15 & 0 & 1 & 0 \\
Proctitis & 4 & 12 & & & 0 \\
Anal pain & & & & 0 & 0 \\
\hline
\end{tabular}

underwent sphincter-sparing surgery, with a 5-year OS of $86 \%$ and a 5 -year DFS of $77 \%$. These results are comparable to the present study in which sphincter-preserving surgery was feasible in $66 \%$ of patients after CRT.

Factors influencing the feasibility of sphincter preservation in our study were tumor distance from the anal verge and tumor downstaging. The majority of patients in our cohort were considered clinically by their surgeons for an APR in relation to the distance of the tumor from the anal verge. Other objective parameters that may have supported this decision were unavailable to us owing to the retrospective nature of the study. The distance from the anal verge is commonly used to describe the tumor location and to assist in decision-making, although it is less accurate than an anatomical description [17]. In a large observational study that evaluated factors predicting sphincter preservation in patients with rectal cancer treated at institutions of the National Comprehensive Cancer Network [18], sphincter-preserving surgery was found to be more likely if the tumor was located $>6 \mathrm{~cm}$ from the anal verge $(\mathrm{OR}=7.7)$. Other predictive factors included younger age at diagnosis, nonfixed tumor, and the operating institution [18]. Pathological tumor downstaging may also reflect tumor downsizing. Indeed, in the present study, the number of pCRs was higher in the LAR than the APR group. Several studies reported a correlation between response to preoperative treatment and sphincter preservation [18-22]. Although all patients in the present study underwent radical excision, the high rates of clinical complete response (with subsequent $\mathrm{pCR}$ ) in low $\mathrm{T} 2$ rectal cancer should also be considered when weighing the possibility of organ preserving treatment in selected patients [22]. Although low pre-CRT carcinoembryonic levels were shown in an earlier study to be associated with tumor response to CRT [22], we found no significant differences in carcinoembryonic levels or other relevant parameters between tumors with or without downstaging.

Preoperative CRT poses a risk of some adverse shortand long-term consequences, including radiation enteritis, diarrhea, ileus, hematologic toxicities and functional anorectal and genitourinary impairments $[6,23,24]$. Although CRT is not recommended for cT2N0 rectal cancer [25], in the present study, it was very well tolerated, with very few, mostly mild treatment-related side effects. This was also reported by Rengan et al. [11].

This study was limited by its retrospective nature and small sample size. Nevertheless, it includes one of the largest cohorts with cT2NO rectal cancer treated with neoadjuvant CRT to date. The retrospective design made it difficult to assess postoperative function. The functional data were retrieved from follow-up charts and showed mild impairment postoperatively in the LAR group, yet none of the patients reported complete incontinence. Additionally, we were unable to compare the groups for postoperative quality of life. Impaired functional outcomes for LAR with preoperative CRT have been well described in the literature $[26,27]$. It appears that patients undergoing sphincter-preserving surgery for rectal cancer have some degree of impaired bowel function, and those treated with radiation, coloanal anastomoses, or hand-sewn anastomoses have significantly worse function regardless of the preoperative tumor stage [11].

In our study, a median number of 8 lymph nodes were retrieved (range 4-17); several studies recommend examination of at least 12 lymph nodes in the colorectal specimen. This number is related to patient prognosis and is used to reflect surgical quality $[28,29]$. Studies that focused on this issue in rectal tumors showed that after long-term CRT, there was a continuous decrease in the number of examined lymph nodes compared to nonirradiated specimens, with the mean number of detected nodes ranging between 4 and 14 per specimen [30,31]. A decrease in the number of retrieved nodes does not represent an inferior oncological outcome [32].

\section{Conclusion}

The current standard treatment for patients with low cT2N0 rectal cancer is APR if an LAR is technically impossible or oncologically unsafe. Our results indicate that preoperative CRT may increase the rate of sphincter preservation without compromising the oncological outcome, with a relatively low rate of treatment-related adverse events. In the current era of multiple therapy options and increased patient participation, neoadjuvant CRT for 
patients with low lying cT2N0 rectal cancer may serve to reduce APR rates in these patient.

\section{Abbreviations}

APR: Abdominoperineal resection; CRT: Chemoradiotherapy; CTV: Clinical target volume; DFS: Disease-free survival; GTV: Gross tumor volume; LAR: Low anterior resection; OS: Overall survival; PCR: Pathological complete response: PTV: Planning target volume.

\section{Competing interests}

The authors declare that they have no competing interests.

\section{Authors' contributions}

NW Participated in the data analysis, design of the study, and drafting of the manuscript. YK Participated in the data acquisition. OP Participated in the data acquisition. AK Participated in revising the manuscript. HK :Participated in drafting and revising the manuscript. ES Participated in the data analysis. EF Participated in the design of the study and revision of the manuscript. BB Participated in the design of the study and revision of the manuscript. All authors have read and approved the final manuscript.

\section{Author details}

'Department of Surgery B, Petach Tikva 49100, Israel. ${ }^{2}$ Davidoff Cancer Center, Rabin Medical Center, Beilinson Campus, Petach Tikva 49100, Israel.

${ }^{3}$ Sackler Faculty of Medicine, Tel Aviv University, Tel Aviv 69978, Israel.

Received: 15 July 2014 Accepted: 8 October 2014

Published online: 22 October 2014

\section{References}

1. Wasserberg N, Gutman H: Resection margins in modern rectal cancer surgery. J Surg Oncol 2008, 98:611-615.

2. Chessin DB, Guillem JG: Abdominoperineal resection for rectal cancer: historic perspective and current issues. Surg Oncol Clin N Am 2005, 14:569-586. vii.

3. Nissan A, Guillem JG, Paty PB, Douglas Wong W, Minsky B, Saltz L, Cohen AM: Abdominoperineal resection for rectal cancer at a specialty center. Dis Colon Rectum 2001, 44:27-36.

4. Tytherleigh MG, Warren BF, Mortensen NJ: Management of early rectal cancer. Br J Surg 2008, 95:409-423.

5. Dahlberg M, Glimelius B, Påhlman L: Improved survival and reduction in local failure rates after preoperative radiotherapy: evidence for the generalizability of the results of Swedish Rectal Cancer Trial. Ann Surg 1999, 229:493-497.

6. Sauer R, Becker H, Hohenberger W, Rödel C, Wittekind C, Fietkau R, Martus P, Tschmelitsch J, Hager E, Hess CF, Karstens JH, Liersch T, Schmidberger H Raab R, German Rectal Cancer Study Group: Preoperative versus postoperative chemoradiotherapy for rectal cancer. N Engl J Med 2004, 351:1731-1740.

7. Ferenschild FT, Dawson I, de Graaf EJ, de Wilt JH, Tetteroo GW: Preoperative radiotherapy has no value for patients with T2-3, NO adenocarcinomas of the rectum. Dig Surg 2009, 26:291-296.

8. Tsai BM, Finne CO, Nordenstam JF, Christoforidis D, Madoff RD, Mellgren A: Transanal endoscopic microsurgery resection of rectal tumors: outcomes and recommendations. Dis Colon Rectum 2010, 53:16-23.

9. Crane CH, Skibber JM, Birnbaum EH, Feig BW, Singh AK, Delclos ME, Lin EH, Fleshman JW, Thames HD, Kodner IJ, Lockett MA, Picus J, Phan T, Chandra A, Janjan NA, Read TE, Myerson RJ: The addition of continuous infusion 5-FU to preoperative radiation therapy increases tumor response, leading to increased sphincter preservation in locally advanced rectal cancer. Int J Radiat Oncol Biol Phys 2003, 57:84-89.

10. Crane $\mathrm{CH}$, Skibber JM, Feig BW, Vauthey JN, Thames HD, Curley SA, Rodriguez-Bigas MA, Wolff RA, Ellis LM, Delclos ME, Lin EH, Janjan NA: Response to preoperative chemoradiation increases the use of sphincter-preserving surgery in patients with locally advanced low rectal carcinoma. Cancer 2003, 97:517-524.

11. Rengan R, Paty P, Wong WD, Guillem J, Weiser M, Temple L, Saltz L, Minsky BD: Distal CT2N0 rectal cancer: is there an alternative to abdominoperineal resection? J Clin Oncol 2005, 23:4905-4912.

12. Kim DW, Lim SB, Kim DY, Kim TH, Jung KH, Kim DH, Chang HJ, Sohn DK, Hong CW, Choi HS, Jeong SY, Park JG: Pre-operative chemo-radiotherapy improves the sphincter preservation rate in patients with rectal cancer located within $3 \mathrm{~cm}$ of the anal verge. Eur J Surg Oncol 2006, 32:162-167.

13. Francois $Y$, Nemoz CJ, Baulieux J, Francois Y, Nemoz CJ, Baulieux J: Influence of the interval between preoperative radiation therapy and surgery on downstaging and on the rate of sphincter-sparing surgery for rectal cancer: the Lyon R90-01 randomized trial. J Clin Oncol 1999, 17:2396.

14. Bujko K, Nowacki MP, Nasierowska-Guttmejer A, Michalski W, Bebenek M, Pudełko M, Kryj M, Oledzki J, Szmeja J, Słuszniak J, Serkies K, Kładny J, Pamucka M, Kukołowicz P: Sphincter preservation following preoperative radiotherapy for rectal cancer: report of a randomised trial comparing short-term radiotherapy vs. conventionally fractionated radiochemotherapy. Radiother Oncol 2004, 72:15-24.

15. Bujko K, Kepka L, Michalski W, Nowacki MP: Does rectal cancer shrinkage induced by preoperative radio(chemo)therapy increase the likelihood of anterior resection? A systematic review of randomised trials. Radiother Oncol 2006, 80:4-12.

16. Rouanet P, Saint-Aubert B, Lemanski C, Senesse P, Gourgou S, Quenet F, Ycholu M, Kramar A, Dubois J: Restorative and nonrestorative surgery for low rectal cancer after high-dose radiation: long-term oncologic and functional results. Dis Colon Rectum 2002, 45:305-313. discussion 313-331.

17. Gonzalez QH, Heslin MJ, Shore G, Vickers SM, Urist MM, Bland KI: Results of long-term follow-up for transanal excision for rectal cancer. Am Surg 2003, 69:675-678.

18. Temple LK, Romanus D, Niland J, Veer AT, Weiser MR, Skibber J, Wilson J, Rajput A, Benson A, Wong YN, Schrag D: Factors associated with sphincter-preserving surgery for rectal cancer at national comprehensive cancer network centers. Ann Surg 2009, 250:260-267.

19. Kong M, Hong SE, Choi WS, Kim SY, Choi J: Preoperative concurrent chemoradiotherapy for locally advanced rectal cancer: treatment outcomes and analysis of prognostic factors. Cancer Res Treat 2012, 44:104-112.

20. Howard JH, Gonzalez Q, Arnoletti JP, Russo S, Fiveash JB, Bland Kl, Heslin MJ: Prognostic factors and preoperative radiation therapy associated with sphincter preservation in patients with resectable rectal cancer. Am J Surg 2008, 195:239-243.

21. Habr-Gama A, Perez RO, Proscurshim I, Campos FG, Nadalin W, Kiss D, Gama-Rodrigues J: Patterns of failure and survival for nonoperative treatment of stage $\mathrm{c} 0$ distal rectal cancer following neoadjuvant chemoradiation therapy. J Gastrointest Surg 2006, 10:1319-1328.

22. Habr-Gama A, Perez R, Proscurshim I, Gama-Rodrigues J: Complete clinical response after neoadjuvant chemoradiation for distal rectal cancer. Surg Oncol Clin N Am 2010, 19:829-845.

23. Marijnen $C A$, van de Velde $C J$, Putter $H$, van den Brink M, Maas $C P$, Martijn H, Rutten HJ, Wiggers T, Kranenbarg EK, Leer JW, Stiggelbout AM: Impact of short-term preoperative radiotherapy on health-related quality of life and sexual functioning in primary rectal cancer: report of a multicenter randomized trial. J Clin Oncol 2005, 23:1847-1858.

24. Peeters KC, van de Velde CJ, Leer JW, Martijn H, Junggeburt JM, Kranenbarg EK, Steup WH, Wiggers T, Rutten HJ, Marijnen CA: Late side effects of short-course preoperative radiotherapy combined with total mesorectal excision for rectal cancer: increased bowel dysfunction in irradiated patients-a Dutch colorectal cancer group study. J Clin Oncol 2005, 23:6199-6206.

25. Valentini V, Glimelius B, Minsky BD, Van Cutsem E, Bartelink H, Beets-Tan RG, Gerard JP, Kosmidis P, Pahlman L, Picciocchi A, Quirke P, Tepper J, Tonato M, Van de Velde CJ, Cellini N, Latini P: The multidisciplinary rectal cancer treatment: main convergences, controversial aspects and investigational areas which support the need for an European Consensus. Radiother Oncol 2005, 76:241-250.

26. Dahlberg M, Glimelius B, Graf W, Påhlman L: Preoperative irradiation affects functional results after surgery for rectal cancer: results from a randomized study. Dis Colon Rectum 1998, 41:543-549.

27. Temple LK, Bacik J, Savatta SG, Gottesman L, Paty PB, Weiser MR, Guillem JG, Minsky BD, Kalman M, Thaler HT, Schrag D, Wong WD: The development of a validated instrument to evaluate bowel function after sphincterpreserving surgery for rectal cancer. Dis Colon Rectum 2005, 48:1353-1365.

28. Goldstein NS: Lymph node recoveries from 2427 pT3 colorectal resection specimens spanning 45 years: recommendations for a minimum number of recovered lymph nodes based on predictive probabilities. Am J Surg Pathol 2002, 26(2):179-189. 
29. Kim YW, Kim NK, Min BS, Lee KY, Sohn SK, Cho CH: The influence of the number of retrieved lymph nodes on staging and survival in patients with stage II and III rectal cancer undergoing tumor-specific mesorectal excision. Ann Surg 2009, 249:965-972.

30. Sobin LH: TNM classification: clarification of number of regional lymph nodes for pNO. Br J Cancer 2001, 85:780.

31. Rinkus KM, Russell GB, Levine EA: Prognostic significance of nodal disease following preoperative radiation for rectal adenocarcinoma.

Am Surg 2002, 68:482-487. v.

32. Kim YW, Kim NK, Min BS, Lee KY, Sohn SK, Cho CH, Kim H, Keum KC, Ahn JB: The prognostic impact of the number of lymph nodes retrieved after neoadjuvant chemoradiotherapy with mesorectal excision for rectal cancer. J Surg Oncol 2009, 100:1-7.

doi:10.1186/s13014-014-0233-3

Cite this article as: Wasserberg et al: Sphincter preservation in distal CT2N0 rectal cancer after preoperative chemoradiotherapy. Radiation Oncology 2014 9:233.

\section{Submit your next manuscript to BioMed Central and take full advantage of:}

- Convenient online submission

- Thorough peer review

- No space constraints or color figure charges

- Immediate publication on acceptance

- Inclusion in PubMed, CAS, Scopus and Google Scholar

- Research which is freely available for redistribution 